\title{
Behaving Badly Online: Establishing Norms of Unacceptable Behaviours
}

\author{
Emma Short ${ }^{1}$, Tyne Stanley ${ }^{1}$, Mick Baldwin ${ }^{1} \&$ Graham Scott $^{2}$ \\ ${ }^{1}$ School of Psychology, University of Bedfordshire, Luton, UK \\ ${ }^{2}$ Division of Applied Psychology, School of Media, Culture and Society, University of the West of Scotland, Paisley, \\ UK
}

Correspondence: Emma Short, School of Psychology, University of Bedfordshire, University Square, Luton, Bedfordshire, LU1 3JU, UK.

Received: November 3, 2014

Accepted: November 21, 2014 Available online: January 13, 2015

doi:10.11114/smc.v3i1.576

URL: http://dx.doi.org/10.11114/smc.v3i1.576

\begin{abstract}
Victims of online abuse suffer measurable negative effects equivalent to survivors of traumas such as bombings and sexual assaults but it has been suggested that the general population view such online behaviour as acceptable, with victims consequently receiving little support. This is an issue of increasing import as the number and accessibility of online communication apps, and their incorporation into our everyday lives, increases the opportunity for Deviant Online Behaviours (DOBs) to be perpetrated. In order to better understand individuals' attitudes to specific DOBs 118 psychology undergraduate students rated 11 examples of DOBs on a scale of severity. Individual difference measures of online cognitions and interpersonal sensitivity were also collected. A factor analysis revealed 3 emerging online behaviour types: use of false information (theft of identity, tricking others), unsolicited behaviour (unsolicited e-mailing/messaging), and persistent communication (frequent contact and use of multiple identities). 'Persistent communication' was viewed as more unacceptable than 'unsolicited behaviour' and 'false information', though all contained behaviours which have been demonstrated to cause severe harm to victims. These findings attempt to demonstrate how individuals categorise deviant online behaviours in terms of severity and individual differences that may be associated with these perceptions.
\end{abstract}

Keywords: cyberpsychology, communication, cyberbullying, cyber-harassment, cyber deviance, cyberstalking, social norms, deviant online behaviours

\section{Introduction}

Hostile and aggressive online behaviours cause measurable distress and wide ranging negative effects on the lives of those being victimised (Bartlett \& Gentile, 2012). Cyberbullying, cyberharassment, and cyberstalking can result in the suffering of both acute and chronic physical, social and emotional symptoms on the part of the victims. Despite these effects it is unclear whether there is a shared understanding of what constitutes online abuse. This paper seeks to contribute to the literature by gathering norms of attitudes towards Deviant Online Behaviours (DOBs) in order to discover which behaviours are classified as unacceptable, and to investigate how individual differences might influence attitudes towards antisocial online behaviour.

\subsection{Deviant Online Behaviours}

A great difficulty exists in defining anti-social online behaviours, with terms such as 'cyberbullying', 'cyberharassment' and 'cyberstalking' often being used interchangeably. A possible explanation for this is the fact that there is an overlap in the specific behaviours involved in the classification of each of these offences. Cyberharassment and cyberstalking have been defined as "Threatening behaviour or unwanted advances directed at another using the Internet and other forms of computer communications" (National Centre for the Victims of Crime, 2003). Like physical stalkers, cyberstalkers intrude into the lives of victims in frightening and unpredictable ways. The difference is that this kind of stalker uses technology and digital media to mediate their activities - they are able to make repeated unwanted intrusions, wherever they or their victim are and at any time (Sheridan \& Grant 2007). These behaviours are also defined as the use of electronic communication to cause fear, alarm or distress made through channels such as email, social networking sites, instant messaging services, webmail or email (Short \& Maple, 2013).

Cyberbullying has traditionally been defined as the use of information and communication technologies to support 
deliberate, repeated and hostile behaviour by an individual or group, which is set up intentionally to cause harm (Belsey, 2004). Such behaviour can be directed to the victim or posted about them, constituting indirect harassment (Jones, Mitchell, \& Finkelhor, 2013), and can be perpetrated via a range of technologies, e.g., text messages, e-mail, instant messaging, and defamatory personal websites. More recently research focus has shifted to the dimensions underlying cyberbullying with imbalance of power, intentionality, and anonymity identified as principal factors across a number of European countries (Mesesini et al., 2012). Cyberbullying has been found to involve the same power dynamics between those involved as traditional offline bullying (Ybarra, Boyd, Korchmaros, \& Oppenheim, 2012) with the principle differences between the two being the degree of anonymity and the size of the audience (Juvonen \& Gross, 2008). Students involved in offline bullying are often also involved in cyberbullying (Burton, Florell, \& Wygant, 2013) but the range of new technologies available to individuals has also been found to increase the chances of victimisation for those who would likely not have been targeted by traditional methods (Mesesini \& Spiel, 2012). With increasing availability of communication apps on smartphones, online and mobile communication methods are becoming increasingly integrated into our everyday lives, and while this offers increased opportunities, it also increases the ways in which individuals may potentially be victimized.

The specific aggressive, or deviant, acts involved in cyberbullying, cyberharassment and cyberstalking are very similar and and can involve aggressive acts across a range of online and mobile communication channels. Distinctions are often determined by the frequency and consistency of attacks (Short \& McMurray, in press). It has been suggested that, based on the diversity of negative acts that can occur across a range of communicative media, research focus should shift to cyber-aggression (Grigg, 2010). Indeed, bullying has been described as a sub-dividion of aggression (Monks, Smith, \& Swettenham, 2005) and bullying, stalking and harassment are often identified as repeated forms of aggression (Dooley, Pyzalski, \& Cross, 2009). For the remainder of this paper we will use the term 'DOBs' when referring generally to aggressive and unacceptable online behaviours directed at other individuals, but when referring to published studies will use the specific terms employed by the original authors. The effects of DOBs on those victimized by them will be discussed before the role of individuals' attitudes in the process is examined, and the necessity of establishing norms of acceptable and unacceptable online behavior outlined.

\subsection{Impact of Deviant Online Behaviours}

DOBs are prevalent in many forms and have wide-ranging negative impacts on the mental, emotional, and social functioning of the abused, the abusers, and those close to them (Bartlett \& Gentile, 2012). In a large scale US study, $8.6 \%$ reported being victims of cyberbullying (Schenk \& Fremouw, 2012). Victims scored higher than matched controls on measures of depression, anxiety, phobic anxiety and paranoia. They also reported experiencing significantly higher levels of suicidal ideations, planning and attempts. Cross-sectional studies have increasingly shown that being a victim of cyberbullying is associated with depression (Perren, Dooley, Shaw, \& Cross, 2010), anger (Li, 2010), conduct and emotional problems (Dooley, Gradinger, Strohmeier, Cross, \& Spiel, 2010), physical pain, smoking, alcohol misuse and feelings of being unsafe while attending school (Sourander et al., 2010).

Social impacts are also recorded by $\mathrm{Li}$ (2010) where results identified the victims of cyberbullying as being more likely to fail at school or avoid school, and are more prone to violence and suicide. Damage may be more severe to those who are bullied online (compared to traditional offline bullying) as the abuse is suffered in domains unlimited by physical boundaries. Harmful material can be broadcast widely online, reaching a larger audience than traditional bullying methods, and is often impossible to track or remove (Juvonen \& Gross, 2008; Li, 2010).

Repeated bullying causes considerable amounts of psychological distress and victims can experience fear of re-victimisation for months (McQuade, 2012). Chronic cases may require psychological intervention or medical treatments if the bullying has been so severe that the victim sees no other way but to attempt to end their life. More common are behavioural changes necessitated by the negative impact of online bullying or harassment: one out of three victims experience symptoms of stress following being bullied or stalked online which has led to them abstaining from the internet (McQuade, 2012) or making other changes to their lives (Maple, Short, Brown, Bryden, \& Salter, 2012) .

The negative effects of DOBs cannot be easily reversed. The prevalence of PTSD following cyber-stalking exceeds the occurrence in a general population following extremely traumatic events (Weathers, Huska, \& Keane, 1994). A study investigating the incidence of trauma found $32.7 \%$ of cyberstalking victims scored highly for all the symptoms of PTSD; this is equivalent to the rates of PTSD recorded by individuals following exposure to severe traumas such as bombing, combat and sexual assaults (Maple et al., 2012).

Adverse outcomes of DOBs effect perpetrators as well as victims. Students who experience cyberbullying as either a victim or perpetrator have significantly lower levels of self-esteem than those who have never been involved with cyberbullying (Patchin \& Hinduja, 2010). Many people who would not bully others face-to-face may be more likely to partake in cyberbullying due to the increased anonymity of their actions and the belief that it is more 'acceptable' to 
engage in such behaviour virtually (Beran \& Li, 2005; Suler 2005).

\subsection{Engagement in Deviant Online Behaviours}

Although much research has investigated the individual characteristics of traditional bullies (e.g., Bosworth, Espelage, \& Simon, 1999; Espelage \& Swearer, 2003), there is little research on the specific characteristics of people who bully online, or the perpetrators of other DOBs. Existing research draws attention to the lack of consensus that has been achieved to date on broad issues in this area (Bauman, 2013).

Some trends have, however, been consistently reported. Distress is high among cyberbullies as well as victims and those who either cyberbully, or are victims of cyberbullying, score higher in psychological symptoms of depression, hostility, interpersonal sensitivity, paranoia, phobic anxiety, and psychoticism. Cyberbullies also experience higher levels of suicidal behaviours and scored higher in aggressiveness, and individuals who are both cyberbullies and victims exhibit higher levels of involvement in violence and drug crimes than cyberbullies and a control group (Schenk, Fremouw, \& Keelan, 2013).The distinction made between perpetrators and victims of DOBs may be a false dichotomy as findings have indicated a correlation between cyberbullying and vicitmisation, suggesting a higher degree of reciprocal behavior in online bullying than in traditional bullying (Bauman, 2013).

While most studies examining the negative effects experienced by the perpetrators of DOBs have focused on cyberbullying in schools, several studies in the field of occupational psychology have investigated individual differences that have the potential to predict Problem Internet Use (PIU) in the adult population. PIU includes behaviour related to spending too much time online, online addiction, and hostile posting, and has been linked to academic and occupational difficulties (Ho \& Lee, 2001). This focus has sought to identify individuals who are likely to engage in online behaviours that could harm themselves, others, or the company which employs them.

The relationship between interpersonal sensitivity and over reliance on social networks for social communication has been established (Wallace, 1999). Heightened interpersonal sensitivity is often presented as being a correlate of self-esteem within interpersonal relationships, causing individuals with this trait to be overly sensitive to perceived criticism or rejection. Boyce and Parker (1989) initially identified five factors of interpersonal sensitivity within clinical and non-clinical groups. This measure has subsequently been used as a construct in the assessment of social anxiety disorder using a three factor model (Harb, Heimberg, Fresco, Schneier, \& Liebowitz, 2001). Links have been identified between social anxiety and increased reliance on online communication (Caplan, 2003) and a propensity to DOB (Davis, Flett, \& Blesser, 2002; Roberts, Smith, \& Pollack, 2000).

The interaction between interpersonal sensitivity and PIU has been explored further in the validation of the Online Cognition Scale (OCS: Davis et al., 2002). This measure was designed to be used in clinical assessment and pre-employment screening of employees for the potential of abuse of the internet in the workplace. The OCS is comprised of four subscales that have been associated with a range of DOBs. 'Impulsivity' was identified as being related risk taking and dangerous behaviours such as sending computer viruses. The second subscale of 'loneliness and depression' was demonstrated to be related to feelings of worthlessness and depressive cognitions relating to the internet. 'Social comfort' was associated with behaviours linked to high sensitivity to rejection such as compiling information about individual in order to avoid rejection. The last subscale is 'distraction', associated with behaviours of procrastination, of which can lead to negative uses of the internet sometimes known as 'cyberslacking' (Greenfield, 1999). Individuals who score highly on such scales may be more prone to take exploit communication opportunities in an online environment, which offers both anonymity and psychological distance, to engage in DOBs and perpetrate acts of cyber-aggression.

\subsection{Attitudes to DOBs and Victims of DOBs}

Despite the negative consequences associated with every aspect of DOBs there is an overwhelming lack of support for victims of such behaviours from agencies and from personal networks (e.g., family, friends, and work colleagues). In Maple et al.'s (2012) study $61 \%$ of participants reported that they received no support whatsoever from agencies or from anyone in their personal network. This absence of support demonstrates a lack of awareness about the toxicity of DOBs on the part of the general population. It also illustrates the a lack of understanding victims face when they find themselves trying to make sense of a situation that may be causing them distress, fear and enforced life changes, and may indicate a lack of appreciation on the part of the general population of the seriousness of deviant acts perpetrated though digital media and online communication channels.

In addition to the lack of support available to people who may become victims of cyberbullying, cyberharassment, and cyberstalking, there is also a worrying growth in the prevalence of individuals engaging in DOBs (Selwyn, 2009). One hypothesis is that this is because social norms have not yet been fully negotiated and established in online domains. The actions of DOBs are unusual in that there is a disproportionate relationship between the ease with which such actions 
can be carried out and the degree of damage they can cause.

The theory that the relationship between antisocial online actions and their consequences is not understood by the majority of domain users is highlighted by $\mathrm{Li}$ (2010) who examined attitudes to cyberbullying in grade 7-12 students. One in five students perceived cyberbullying as a 'cool' act. The authors propose that this finding may be explained by students viewing technology as exciting, and its utilization for aggressive acts as creative. Additionally, Li suggests that students may not realise the seriousness of cyberbullying, as one student stated that they bullied online as 'it does not mean anything', demonstrating a failure to appreciate the negative effects that such DOBs can have on those they are perpetrated against. Almost half of the students believed that although cyberbullying is bad, nothing can be done about it and one in six believed that people have the right to say whatever they like even if it hurts someone or violates their privacy. This sense of inevitability may be related to the range of communication channels over which the DOBs involved in cyberbullying may be committed, and a diffusion of responsibility around which rule govern behaviours in such domains.

These conclusions are consistent with a body of literature which suggests that there is an absence or conflict of social conventions in online environments that might regulate behaviour (e.g., Beran \& Li, 2005). Further work in this area hypothesises that this lack of convention may be linked to a disinhibition effect and increased aggression not only in online exchanges, but in other communications carried out using technology (Short and McMurray, 2009; Suler, 2005).

\subsection{The Current Study}

In order to establish current attitudes regarding what constitutes unacceptable behaviour online, individuals' attitudes towards specific behaviours will be measured. This will provide an insight into the norms that are emerging in online domains. Given the prevalence and diversity of DOBs, the severe and lasting implications for victims, and ambiguity associated with certain online behaviours, it is important that the public's attitudes towards the acceptability of specific behaviours are known. The aim is not to define any behavior (or group of behaviours) under terms such as 'cyberbullying', but to discover how a range of different categories of DOBs, each of which have been associated with negative effect in those victimized, are considered by a group of participants who are active users of the internet and other forms of communication technology, and whose attitudes both therefore reflect and contribute to the online norms which govern the behaviour of individuals in digital domains across a range of media.

To identify emerging social norms of the acceptability of specific aggressive online behaviours, participants in the current study will rate a number of specific behaviours on a scale of acceptability. Their responses will also be used to ascertain any factor structure within this range of behaviours. To ascertain how individual differences already identified as being associated with PIU may influence attitudes to range of DOBs presented, the Online Cognitions and Interpersonal Sensitivity of participants will also be measured. It is hypothesised that clusters of DOBs will emerge, with some being rated as more unacceptable than others.

Table 1. List of items from the Aggressive Online Behaviour Questionnaire

\begin{tabular}{ll}
\hline Item Number & Behaviour \\
\hline 1 & $\begin{array}{l}\text { One individual seeking and compiling information about other individual and using it to harass, } \\
\text { threaten and intimidate him/her on- or off-line }\end{array}$ \\
& Repeated unsolicited e-mailing from one individual. \\
3 & Repeated unsolicited Instant Messaging from one individual. \\
4 & Electronic sabotage such as spamming and sending of viruses by one individual. \\
5 & Theft of the individual's identity by other individual. \\
6 & One individual subscribing other individual to services without his/her knowledge or permission. \\
7 & One individual purchasing goods and services in other individual's name without his/her knowledge or \\
8 & permission. \\
9 & $\begin{array}{l}\text { One individual using different identities in an attempt to contact other individual on-line. } \\
\text { One individual sending or posting hostile material, misinformation and false messages about other }\end{array}$ \\
10 & $\begin{array}{l}\text { Ondividual (e.g. to use net groups). } \\
\text { posting my personal details on a bulletin board) }\end{array}$ \\
& One individual making frequent (more than once a day) mobile phone calls or texts to other individual. \\
\hline
\end{tabular}

Table 1 shows the items from the Aggressive Online Behaviour Questionnaire (Adapted from Sheridan and Grant, 2007). Participants rated these on a scale of severity from 1 (acceptable behaviour) to 6 (cyberstalking). 


\section{Method}

\subsection{Design and Participants}

The study utilized a correlational design and measured participants' attitudes to Aggressive Online Behaviour, Interpersonal Sensitivity, and Online Cognitions. One-hundred and eighteen undergraduate psychology students (96 women, age range: $18-49$, Mean=23.24, $\mathrm{SD}=7.31$ ) participated as part of their undergraduate lecture course.

\subsection{Materials}

Participants' attitudes to aggressive online behaviour were measured using the Classifications of Aggressive Online Behaviour Questionnaire (Adapted from Sheridan \& Grant, 2007). This listed 11 examples of aggressive online behaviours which are shown in Table 1. Participants were required to rate each statement on a six-point scale on how unacceptable they viewed that behaviour to be ( $1=$ acceptable behaviour, $6=$ cyberstalking).

Interpersonal sensitivity was measured using the Interpersonal Sensitivity Measure (Boyce \& Parker, 1989). This comprised a total of 29 items and contained three subscales: Interpersonal Worry and Dependency (11 items: Cronbach's alpha $=0.84$, alpha in original paper $=0.88$ ), Low Self-esteem (10 items: Cronbach's alpha $=0.54$, alpha in original paper $=0.33$ ), and Unassertive Interpersonal Behaviour ( 8 items: Cronbach's alpha $=0.69$, alpha in original paper $=0.79)$. Respondents rated each item along a 4-point scale ( $1=$ very unlike me, $4=$ very like me).

Online cognitions were measured using the Online Cognition Scale (Davis, Flett, \& Besser, 2002). This comprised a total of 36 items and contained four subscales: Social Comfort (13 items: Cronbach's alpha=0.90, alpha in original paper $=0.87$ ), Loneliness/Depression (6 items: Cronbach's alpha $=0.91$, alpha in original paper $=0.77$ ), Diminished Impulse Control (10 items: Cronbach's alpha $=0.97$, alpha in original paper $=0.84)$, and Distraction $(7$ items: Cronbach's alpha $=0.97$, alpha in original paper $=0.81)$. Respondents rated each item along a 7 -point Likert scale $(1=$ disagree strongly, 7 = agree strongly).

\subsection{Procedure}

Participants attending a university lecture were given initial briefing on how to complete the questionnaires, which were presented to them in a booklet in the order detailed in the materials section together with instructions, a consent form, and a debriefing sheet. The study conformed to the School's ethical guidelines and participants were free to not take part or to withdraw from the study at any time, and all data was stored anonymously. The study took around 10 minutes to complete.

\section{Results}

Initially, a factor analysis was carried out in order to define categories of unacceptable behaviours. An ANOVA was then employed to assess whether there were any differences between these categories. Finally, a regression was conducted to assess what individual differences predicted how participants view unacceptable behaviours.

\subsection{Factor Analysis: Identifying Categories of Unacceptable Online Behaviours}

The factorability of the Aggressive Online Behaviour Questionnaire scale was examined. The Kaiser-Meyer-Olkin measure of sampling adequacy $=0.75$, above the recommended value of .6 , and Bartlett's test of sphericity was significant $\left(\chi^{2}(45)=375.94, p<0.001\right)$, meaning the values can be accurately correlated. The diagonals of the anti-image correlation matrix were all over 0.6 and communalities all above 0.5 . Together, these indicators suggested factor analysis was appropriate for all 11 items of the scale. Participants' classifications of aggressive online behaviours were factor analysed using principal component analysis with Varimax (orthogonal) rotation.

Initial analysis yielded four factors, explaining $68.54 \%$ of the total variance. However, items one, four and five loaded higher than 0.3 on two factors, so were excluded from the analysis. The final analysis yielded three factors, explaining $67.75 \%$ of the total variance (see Table 2).

Factor 1: Use of False information consisting of items six, seven, nine and ten explained $36.89 \%$ of the variance $(\alpha=0.70)$, which encompasses: theft of identity, subscribing to services as someone else, tricking others, and purchasing goods as someone else.

Factor 2: Unsolicited Behaviour consisting of items two and three explained $17.85 \%$ of the variance $(\alpha=0.88)$, which encompasses: unsolicited e-mailing and unsolicited messaging.

Factor 3: Persistent Communication consisting of items eight and eleven explained $13.01 \%$ of the variance $(\alpha=0.53)$, which encompasses: using different identities and frequent contact. 
Table 2. Factor loadings and communalities based on Principle Components Analysis

\begin{tabular}{lllll}
\hline Item & $\begin{array}{l}\text { False } \\
\text { Information }\end{array}$ & $\begin{array}{l}\text { Unsolicited } \\
\text { Behaviour }\end{array}$ & $\begin{array}{l}\text { Persistent } \\
\text { Communication }\end{array}$ & Communality \\
\hline 2 & & 0.93 & & 0.87 \\
3 & 0.92 & & 0.88 \\
6 & 0.60 & & 0.46 \\
7 & 0.61 & 0.77 & 0.47 \\
8 & & & 0.69 \\
9 & 0.78 & & 0.60 \\
10 & 0.84 & & 0.83 & 0.70 \\
11 & & & 0.73 \\
\hline
\end{tabular}

As shown in Table 2, 8 of the 11 items from the Aggressive Online Behaviour Questionnaire load onto 3 factors when analysed via Principle Components Analysis with Varimax Rotation ( $\mathrm{N}=118)$.

\subsection{ANOVA: Assessing Differences between Categories of Unacceptable Online Behaviours}

The results of a one-way within-participants ANOVA revealed a significant difference between categories of Unacceptable Online Behaviours $\left[F(2,234)=13.27, p<0.001, \eta^{2}=0.102\right]$. Bonferroni post hoc tests revealed a significant difference $(p<0.001)$ between Persistent Communication (mean=4.89, $\mathrm{SD}=0.24)$ and Use of False Information (mean=4.29, $\mathrm{SD}=0.79)$ and a significant difference $(p<0.05)$ between Persistent Communication and Unsolicited Behaviour (mean=4.52, $\mathrm{SD}=0.16$ ). There was no significant difference between Unsolicited Behaviour and Use of False Information. Persistent Communication was perceived as more severe than Unsolicited Behaviour or Use of False information.

\subsection{Regression: Predicting Views of Unacceptable Behaviours}

Three standard multiple regressions were conducted in order to assess whether participants' scores on the sub-scales of Interpersonal Sensitivity (Interpersonal Worry and Dependency, Low Self-esteem, Unassertive Interpersonal Behaviour) and Online Cognition (Social Comfort, Loneliness/Depression, Diminished Impulse Control, and Distraction) were able to predict participants' attitudes towards the three identified categories of unacceptable online behaviour (Use of False Information, Unsolicited Behaviour, Persistent Communication).

The first standard multiple regression identified that scores on the psychometric measures were able to predict $3.8 \%$ of the variability in attitudes towards Use of False Information. This was not significant $[F(7,111)=1.65, p>0.05]$. The second standard multiple regression identified that scores on the psychometric measures were able to predict $0.7 \%$ of the variability in attitudes towards Unsolicited Behaviour. This was not significant $[F(7,111)=1.12, p>0.05]$. The third standard multiple regression identified that scores on the psychometric measures were able to predict $5.7 \%$ of the variability in attitudes towards Persistent Communication. This was marginally significant $[F(7,110)=2.01, p=0.60]$. Loneliness was a significant predictor $[\beta=0.384, p<0.05]$ with Social comfort marginally significant $[\beta=-0.272, p=.057]$.

\section{Discussion}

There is a general consensus in the existing literature that there is an absence of social conventions in online environments that might regulate behaviour (Beran \& Li, 2005). There is also evidence that this lack of convention may be linked to a disinhibition effect and increased aggression in online exchanges (Suler, 2005). The aim of our study was primarily to identify any emerging social norms of behaviour types and attitudes towards the acceptability of aggressive online behaviours. In addition, the study sought to establish links with measures of online cognitions, and to establish links with general measures of Interpersonal Sensitivity due to evidence of their role in precipitating problem internet use and DOBs (Boyce \& Parker, 1989; Davis et al., 2002; Wallace, 1999). Therefore this study attempted to investigate the inconsistency between the extent of measurable impacts of online abuse and the apparent diversity of attitudes towards the acceptability of such behaviours.

Participants were presented with a range of hostile DOBs which they were required to rate on a scale of perceived severity. When the data were analysed three factors emerged which we defined as 'Use of False Information', 'Unsolicited Behaviour' and 'Persistent Communication'. This indicates that a shared understanding of the grouping of specific behaviours exists, which suggests the emergence of social norms for behaviour in online environments.

'Persistent Communication' referred to the frequency and duration of behaviour and the use of multiple identities under which the behaviour was conducted. Persistent, intrusive communication as a form of harassment has been reported consistently in the literature. Previous research has identified this behavioural element in cyberstalking and cyberbullying and persistence, along with frequency, is identified as the primary criteria used to define stalking (Purcell, 
Pathe, \& Mullen, 2004). Such is the recurrence of this feature that researchers investigating perceptions of cyberstalking have even provided vignettes to elicit participant responses that explicitly feature this aspect of harassing behaviour (Alexy, Burgess, Baker, \& Smoyak 2005).

'Use of False Information' referred to the posting of untrue information online, or the perpetrator(s) posing as the victim online and ordering services, purchasing goods, or using their identity to make comments likely to attract negative comment. This aspect of harassing behaviour is consistent with findings is previous literature which have highlighted this as a behaviour reported by victims of bullying and harassment (Belsey, 2004; Sheridan \& Grant, 2007). Research seeking to more specifically define different types of cyberbullying have labelled these forms of behaviour as 'denigration' (Willard, 2004).

'Unsolicited Behaviour' included repeated communication that was not sought by the recipient. Victims of cyberharassment consistently report unsolicited communication as a characteristic of their experience (Beran \& $\mathrm{Li}$, 2005). Interestingly, unsolicited intrusion is the main criteria of harassment and is judged in its severity by the degree of persistence along with frequency of communications in Purcell et al.'s (2001) model used to identify stalking.

Participants' categorisation of the acceptability of the three factors of varied. Overall, 'Persistent Communication' was perceived as more severe than 'Unsolicited Behaviour' or 'Use of False Information'. 'Persistent Communication' was comprised of the behaviours 'using different identities' and 'frequent contact'. This is partly consistent with previous research that indicates the persistence of communication, and the number of channels or identities through which that communication is made, is directly related to the degree of fear and distress experienced by individual targeted by such behaviours (Maple et al., 2012). Indeed, stalking is defined by the number of intrusions made (Protection of Freedoms act, 2012). The identified categories contained a range of behaviours which reflected both direct and indirect aggression towards the victim, and which can be perpetrated via a number of online communications channels, and via a range of technological devices.

Some behaviours which have been shown to contribute to severe negative effects on the part of victims of abuse in online domains were not recognised in the current study as being particularly unacceptable. Unsolicited intrusion (by means of repeated emailing and instant messaging) for example, has been shown to be a key component in what defines cyberstalking, an activity which can elicit symptoms of PTSD in those victimised. This was shown to belong to the 'Unsolicited behaviour' category of behvaiours which were perceived as less unacceptable then 'Persistent Communication'. This demonstrates that while social norms relating to unacceptable online behaviours are emerging, these are not necessarily forming in line with the consequences of the actions. Specifically, the consequences of DOBs perpetrated through an increasing range of non-traditional communication channels are not recognised by users of such channels, and are therefore not reflected in the norms emerging to govern behaviour is these domains.

More needs to be done to investigate the cognitions behind such attitudes so they can then be challenged and brought into line with the effects such behaviours have on victims. By educating users of online domains about the potential distress and suffering certain online behaviours can have, attitudes towards these behaviours will change, and the social norms which are forming in such environments will change to better reflect real-word consequences. It has been pointed out that restriction of access to technologies in some real world domains (e.g., the banning of phones in schools) will do nothing to combat the prevalence of DOBs if individuals have access to said technologies in other real-world environments. Educational measures are required to change shared understanding and social cognitions of the consequences of DOBs, and therefore their acceptability in all online domains, if behaviours are to change (Pfetsch, Steffgen, \& König, 2009; cited in Grigg, 2010).

This research also investigated the extent to which individual differences might predict perceptions of aggressive online behaviours. The results indicated limited evidence of a relationship between some individual difference measures and the degree of severity with which participants categorised online harassment behaviours involving 'persistent communication'. This behavioural category was considered to be the most serious form of online harassment, consistent with much of the previous literature (Maple et al., 2012; Purcell et al., 2004; Sheridan \& Grant, 2007). The results from the regression analysis indicate that marginal findings were found in predicting the variability in attitudes towards Persistent Communication. Both came from the online cognition scale: loneliness/depression and social comfort. Interpersonal Sensitivity was not found to predict any variability of scores. No similar effects were found for scores from the other two factors of 'Use of False Information' and 'Unsolicited Behaviour'.

The lack of significant findings relating to the effects of individual differences in predicting attitudes towards DOBs is at odds with previous research (e.g., Davis et al., 2002; Roberts et al., 2000). It may be that the absence of firm relationships between the individual difference measures adopted in this study, and attitudes to online harassment, are a reflection of emerging social norms in online environments. This would imply that the influence of social norms in online domains govern communication behaviours to a greater degree than individual differences, but that at the 
moment such norms do not reflect the negative consequences of certain aggressive behaviours.

However, this cannot be definitively concluded based on the current results. Further work should include other individual difference measures, such as empathy and self-esteem, which have consistently demonstrated predictive power in attitudes to cyberbullying with larger participant groups. Global Self-esteem has consistently been found to predict both preference for online communication and problematic internet use (Caplan, 2003; Wallace, 1999). Self-esteem was included in the current study represented by one of the dimensions of the Interpersonal Sensitivity Measure, however this measure differs from the global measure generally used in existing research (Rosenberg, 1965). Rosenberg's measure includes items that reflect feelings of personal worth and value, such as 'at times I feel I am no good at all and 'all in all, I am inclined to think I am a failure', it does not address beliefs about esteem from others. The measure used the current study was focused on interpersonal engagement and therefore lists items that are concerned with the esteem of others and knowledge of being able to positively relate to others, such as the reverse items 'I feel that people generally like me' and 'I can make other people feel happy'. It may be that beliefs about personal value, rather than the evaluation of being valued by others are more associated with perceptions of DOB and could be included in further work.

Another individual difference that had been found to predict perceptions and enactments of DOBs is empathy. A negative relationship has been demonstrated between empathy and aggressive online behaviors (Steffgen, Konig, Pfetsch, \& Melzer, 2011). Cyberbullies demonstrate a lack of affective empathy, and high levels of moral disengagement compared to non-bullies Renati et al (2012), and are more afraid of becoming victims of cyberbullying themselves, thereby strengthening the research on the relationship between empathy and aggressive behaviour (Steffgen et al., 2011).

It could be the case that the measures of individual differences used here reflect only an inclination on the part of individuals to engage in certain behaviours, not an awareness of how acceptable a certain behaviour is, or how potentially damaging its consequences. This would indicate that norms of unacceptable online behaviour are beginning to emerge, and that a majority of users are aware of their existence, but that certain characterological traits mean that some individuals are still more likely to engage in such behaviours regardless. An individual who scores highly on the Interpersonal Sensitivity subscale of self-esteem, for example, might be more likely to engage in a certain type of DOB (Caplan, 2003; Wallace 1999), but they would do this despite knowing that the behaviour was unacceptable. Future research could focus on the link between such tendencies and the roles of power and anonymity, both of which have been identified as factors in cyberbullying (Mesesini et al., 2012) and may lead to an understanding of the propensity of individuals to engage in DOBs via different communication channels, and on different technological devices.

\subsection{Conclusions}

The current results suggest that various types of anti-social online behaviours are being viewed differently in terms of their seriousness and the degree of harm they can cause. Behaviours in the category of 'Persistent Communication' are considered to be the most unacceptable, with those belonging to the categories of 'Use of False Information' and 'Unsolicited Behaviour' perceived as being less severe. This is indicative of a low level of awareness about the impact and the implication of involvement in DOBs, as behaviours associated with each of these categories have been shown to produce serious and lasting negative effects for victims. Results from this work suggest that a significant number of people perceive aggressive acts perpetrated online and via mobile communication technologies, that have negative impacts on others, as harmless. More research in this area is necessary to consolidate understanding of this and influence emerging social norms of online communication behaviour.

\section{References}

Alexy, E. M., Burgess, A. W., Baker, T., \& Smoyak, S. (2005). Perceptions of cyberstalking among college students. Brief Treatment and Crisis Intervention, 5, 279-289. http://dx.doi.org/10.1093/brief-treatment/mhi020

Bartlett, C. P., \& Gentile, D. A. (2012). Attacking others online: the formation of cyberbullying in late adolescence. Psychology of popular media culture, 1(2), 123-135. http://dx.doi.org/10.1037/a0028113

Bauman, S. (2013). Cyberbullying: What Does Research Tell Us? Theory Into Practice, 52(4), 249-256.

Belsey, B. (2004). Cyberbullying, An Emerging Threat to the 'Always-on' Generation. Retrieved 22 December 2013 from www.cyberbullying.ca.

Beran, T., \& Li, Q. (2005). Cyber-harassment: a new method for an old behaviour. Journal of Educational Computing Research, 32(3), 265-277. http://dx.doi.org/10.2190/8YQM-B04H-PG4D-BLLH

Bosworth, K., Espelage, D. L., \& Simon, T. R. (1999). Factors associated with bullying behaviour in middle school students. Journal of Early Adolescence, 19, 341-362. http://dx.doi.org/10.1177/0272431699019003003 
Boyce, P., \& Parker, G. (1989). Development of a scale to measure interpersonal sensitivity. Australian and New Zealand Journal of Psychiatry, 23(3), 341-351.

Burton, K. A., Florell, D., \& Wygant, D. B. (2013). The role of peer attachment and normative beliefs about aggression on traditional bullying and cyberbullying. Psychology in the Schools, 50(2), 103-115. http://dx.doi.org/10.1002/pits.21663

Caplan, S. E. (2003). Preference for online social interaction: a theory of problematic internet use and psychosocial well-being. Communication Research, 30(6), 625-642. http://dx.doi.org/10.1177/0093650203257842

Communications Act (2003) Communications Act. Retrieved 2 March 2012 from www.legislation.gov.uk/ukpga/2003/21/section/127

Davis, R. A., Flett, M. A., \& Besser, A. (2002). Validation of a new scale for measuring problematic internet use: implication for pre-employment screening. Cyber Psychology and Behaviour, 5(4), 331-345. http://dx.doi.org/10.1089/109493102760275581

Dooley, J. J., Pyzalski, J., \& Cross, D. (2009). Cyberbullying versus face-to-face bullying: A theoretical and conceptual review. Zeitschrift für Psychologie/Journal of Psychology, 217(4), 182-188. http://dx.doi.org/10.1027/0044-3409.217.4.182

Dooley, J. J., Gradinger, P., Cross, D., Strohmeier, D., \& Spiel, C. (2010). Cyber-victimisation: The association between help seeking and mental health symptoms in adolescents from Australia and Austria. Australian Journal of Guidance and Counselling, 20 (2), 194-210. http://dx.doi.org/10.1375/ajgc.20.2.194

Espelage, D. L., \& Swearer, S. M. (2003). Research on school bullying and victimization: What have we learned and where do we go from here? School Psychology Review, 32, 365-383.

Greenfield, D. N. (1999). Virtual addiction: help for netheads, cyberfreaks, and those who love them. Oakland, CA: New Harbinger Publications.

Grigg, D. W. (2010). Cyber-aggression: Deffinition and concept of cyberbullying. Australian Journal of Guidance \& Counselling, 20(2), 143-156. http://dx.doi.org/10.1375/ajgc.20.2.143

Harb, G. C., Heimberg, R. G., Fresco, D. M., Schneier, F. R., \& Liebowitz, M. R. (2002). The psychometric properties of the interpersonal sensitivity measure in social anxiety disorder. Behaviour Research and Therapy, 40, 961-979. http://dx.doi.org/10.1016/S0005-7967(01)00125-5

Ho, S. M., \& Lee, L. M. (2001). Computer usage and its relationship with adolescent lifestyle in Hong Kong. Journal of Adolescent Health, 29, 258-266. http://dx.doi.org/10.1016/S1054-139X(01)00261-0

Jones, L. M., Mitchell, K. J., \& Finkelhor, D. (2013). Online Harassment in Context: Trends from Three Youth Internet Safety Surveys (2000, 2005, 2010). Psychology of Violence, 3(1), 53-69.

Juvonen, J., \& Gross, E. (2008). Extending the school grounds?-Bullying experiences in cyberspace. Journal of School Health, 78, 496 - 505. http://dx.doi.org/10.1111/j.1746-1561.2008.00335.x

Li, Q. (2010). Cyberbullying in high schools: a study of students' behaviours and beliefs about this new phenomenon. Journal of aggression, maltreatment and trauma, 19, 372-192. http://dx.doi.org/10.1080/10926771003788979

Maple, C., Short, E., Brown, A., Bryden, C., \& Salter, M. (2012). Cyberstalking in the UK: Analysis and Recommendations. International Journal of Distributed Systems and Technologies, 3(4), 34-51. http://dx.doi.org/10.4018/jdst.2012100104

McQuade, S. C. (2012). Cyberstalking and Cyberbullying. New York: Chelsea House.

Menesini, E., Nocentini, A., Palladino, B. E., Frise'n, A., Berne, S., Ortega-Ruiz, R., \& Smith, P. K. (2012). Cyberbullying definition among adolescents: A comparison across six European countries. Cyberpsychology, Behaviot, \& Social Networking, 15(9), 455-463. http://dx.doi.org/10.1089/cyber.2012.0040

Mesesini, E., \& Spiel, C. (2012). Introduction: Cyberbullying: Development, consequences, risk and protective factors. European Journal of Developmental Psychology, 9(2), 163-176. http://dx.doi.org/10.1080/17405629.2011.652833

Monks, C. P., Smith, K. P., \& Swettenham, J. (2005). Psychological correlates of peer victimisation in preschool: Social cognitive skills, executive function and attachment profiles. Journal of Aggressive Behaviour, 31, 571-588. http://dx.doi.org/10.1002/ab.20099

National Centre for the Victims of Crime [USA] (2003). Cyberstalking. Available at http://www.ncvc.org/ncvc/main.aspx?dbName=DocumentViewer\&DocumentID=32458 (accessed 7 September, 2009). 
Olweus, D., (1996). The Revised Olweus Bully/Victim Questionaire. Bergen, Norway. Research Center for Health Promotion (HMTL), University of Bergen.

Patchin, J. W., \& Hinduja, S. (2010). Cyberbullying and self-esteem. Journal of School Health, 8(12), 614-621. http://dx.doi.org/10.1111/j.1746-1561.2010.00548.x

Perren, S., Dooley, J. J., Shaw, T., \& Cross, D. (2010). Being victimized in school and cyberspace: Associations with depressive symptoms in Swiss and Australian adolescents. Child and Adolescent Psychiatry and Mental Health, 4, $1-10$.

Protection of Freedoms Act (2012). Retrieved 25 Octover 2014 from http://www.legislation.gov.uk/ukpga/2012/9/contents/enacted

Purcell, R., Pathe, M., \& Mullen, P. E. (2004). Stalking: Defining and prosecuting a new category of offending. International Journal of Law and Psychiatry, 27, 157-169. http://dx.doi.org/10.1016/j.ijlp.2004.01.006

Renati, R., Berrone, C., \& Zanetti, M. A. (2012). Morally disengaged and unempathic: do cyberbullies fit these definitions? An exploratory study. Cyberpsychology, Behavior, \& Social Networking, 15(8), 391-398. http://dx.doi.org/10.1089/cyber.2012.0046

Roberts, L. D., Smith, L. M., \& Pollock, C. M. (2000). "U r a lot bolder on the net" shyness and internet use. In Cozier RW (ed) Shyness: development, consolidation and change. New York: Routledge, 121-138.

Rosenberg, M. (1965). Society and the adolescent self-image. Princeton, NJ: Princeton University Press.

Schenk, A. M., Fremouw, W. J., \& Keelan, C. M. (2013). Characteristics of college cyberbullies. Computers in human behaviour, 29 (6), 2320-2327. http://dx.doi.org/10.1016/j.chb.2013.05.013

Selwyn, N. (2009). A safe haven for Misbehaving online: An Investigation of Online Misbehavior Among Undergraduates. Social Science Computer Review, 26(4), 446-465. http://dx.doi.org/10.1177/08944339307313515

Sheridan, L. P., \& Grant, T. (2007). Is cyberstalking different? Psychology, Crime \& Law 13(6): 627-640.

Short, E., \& Maple, C. (2013). 'Cyberstaking'. Presented at the National Stalking Awareness Day Conference, 'Know the law, use the Law' held by the Susie Lamplugh Trust and the National Stalking Helpline on April $18^{\text {th }} 2013$.

Short, E., \& McMurray, I. (2009) Does being a mobile phone user put individuals at increased risk of experiencing harassment? Human Technology, 5(2), 163-180.

Short, E., \& McMurray, I. (In press) An Exploration Of Intrusive Mobile Phone Behaviour'. In Z. Yan (Ed). Encyclopedia of Mobile Phone Behaviour. In Z. Yan (Ed.), Encyclopedia of Mobile Phone Behavior 1, 2, \& 3. Hershey, PA: IGI Global.

Sourander, A., Klomek, A. B., Ikonen, M., Lindroos, J., Luntamo, T., \& Koskelainen. (2010). Psychosocial risk factors associated with cyberbullying among adolescents: A population-based study. Archives of General Psychiatry, 67(7), 720-728. http://dx.doi.org/10.1001/archgenpsychiatry.2010.79

Steffgen, G., König, A., Pfetsch, J., \& Melzer, A. (2011). Are cyberbullies less empathic? Adolescents' cyberbullying behaviour and empathic responsiveness. Cyberpsychology, behaviour and social Networking, 14(11), 643-648. http://dx.doi.org/10.1089/cyber.2010.0445

Suler, J. (2005). The Online Disinhibition effect. International Journal of Applied Psychoanalytic Studies 2 (2), 184-188. http://dx.doi.org/10.1089/1094931041291295

Wallace, P. (1999). The psychology of the Internet. Cambridge: Cambridge University Press. http://dx.doi.org/10.1017/CBO9780511581670

Weathers, F. W., Litz, B. T., Huska, J. A., \& Keane, T. M. (1994). The PTSD Checklist-Civilian Version. In American Psychiatric Association. Diagnostic and Statistical Manual of Mental Disorders ( $4^{\text {th }}$ ed). Washington, DC: American Psychiatric Association.

Willard, N. (2004). Educator's guide to cyberbullying: Addressing the harm caused by online social cruelty. Retrieved 20 December 2009 from http://cyberbully.org

Ybarra, M., Boyd, D., Korchmaros, J., \& Oppenheim, J. (2012). Defining and measuring cyberbullying within the larger context of bullying victimisation. Journal of Adolescent Health, 5(1), 53-58.

\section{(cc) BY}

This work is licensed under a Creative Commons Attribution 3.0 License. 